\title{
viewpoint
}

\section{Research in China}

\author{
Experiences from 23 years of molecular genetics research in Shanghai
}

\author{
Wolfgang Hennig
}

M y stay in China began in November 1985 with a lecture at the opening of the Max Planck Guest Laboratory in the Institute of Cell Biology at the Chinese Academy of Sciences (CAS) in Shanghai (Hennig, 2000). It marked the beginning of 23 years of research and teaching at the Institute of Cell Biology and other universities throughout China.

\section{Looking back after 23 years, the changes that have taken place in China could not have been predicted in $1985 .$.}

In January 2001, I accepted a longterm lectureship offered by the German Academic Exchange Service (DAAD; Bonn, Germany), which, with further support from CAS, allowed me to create my own research group within the Shanghai Institutes for Biological Sciences (SIBS). During the next five years, 32 German and seven Chinese students worked in my laboratory, including three PhD students-two Chinese, one German-seven German diploma students, one Chinese Master student and one Chinese Bachelor student, as well as several Chinese and German undergraduate students. As the rules of the German diplomatic service state that activities in foreign countries must be limited to five years, my contract with SIBS expired in January 2006.

In 2005, the Max Planck Society (Munich, Germany) had established a Partner Institute with CAS that was dedicated to computational biology, and which extended the cooperation that had begun 20 years earlier with the Max Planck Guest Laboratory in Shanghai. I joined the Institute in May 2006 to participate in the development of the 'Toponome Center'-a microscopy facility for mapping protein patterns (Schubert et al, 2006). This project eventually failed owing to difficulties in establishing the necessary facilities, and I decided to terminate my activities in China in late 2008.

During more than 20 years in Shanghai, I naturally became engaged in several additional projects that have furnished me with first-hand experience of many aspects of Chinese universities and research facilities, as well as the Chinese education system. I have also met many Chinese families privately and have discussed their problems and views with them. In addition, one of my main tasks has been to interview Chinese candidates for PhD programmes and postdoctoral positions on behalf of DAAD and several European universities and research institutes; in total, more than 1,000 interviews. As such, one of my most unexpected experiences has been that-contrary to the often-cited cultural differences-both Chinese and European students share much the same basic attitudes and ambitions.

L ooking back after 23 years, the changes that have taken place in China could not have been predicted in 1985; at first glance, one might even be tempted to say that today every aspect of Chinese life has changed. A visitor to Shanghai in 2008, who had made a single, first visit in 1985, would not recognize it as the same cityand the same holds true for all major cities in China, from Beijing to Wuhan or Chengdu. But it is not just the city's architecture and volume of traffic that has changed; the legal and political climates, as well as the daily life of its citizens, have also changed markedly. Travelling to the countryside, however, presents a very different picture. My son, for example, carried out an exhausting three-month agricultural project-as part of a cooperation between the University of Cologne, Germany, and the Beijing Agricultural University-in a rural area of the Shandong province; though, as a foreign visitor, he still fared much better than the farmers in the same village.

Dramatic changes have also taken place in Chinese academic research as the country has advanced economically. Until the late 1990s, it was still necessary to carry almost everything that was needed for a practical course in one's personal luggage, as it was hard to get the necessary material within China itself. Today, most equipment and consumables are available, although delivery can be exceptionally slow (Fig 1)—we once had to wait four months for Drosophila plastic vials to arrive from a German company, even though the company has a representative in China. Similarly, it once took two months for the standard radiochemical ${ }^{32} \mathrm{P}-\mathrm{dCTP}$ to be delivered.

\section{A serious problem is that politics and political manoeuvring still have a large impact on matters that should be purely scientific}

The quality of the research equipment has improved considerably: in the 1980s and 1990s, most tools and machines were either missing, in bad condition or were unusable. Once, in the early 1990s, while reading the user manual of a preparative ultracentrifuge in Shanghai, I found that the centrifuge had not even been used for two years-not surprising given that the materials required for its use, such as caesium chloride, were not then available at sufficient quality. Today, 


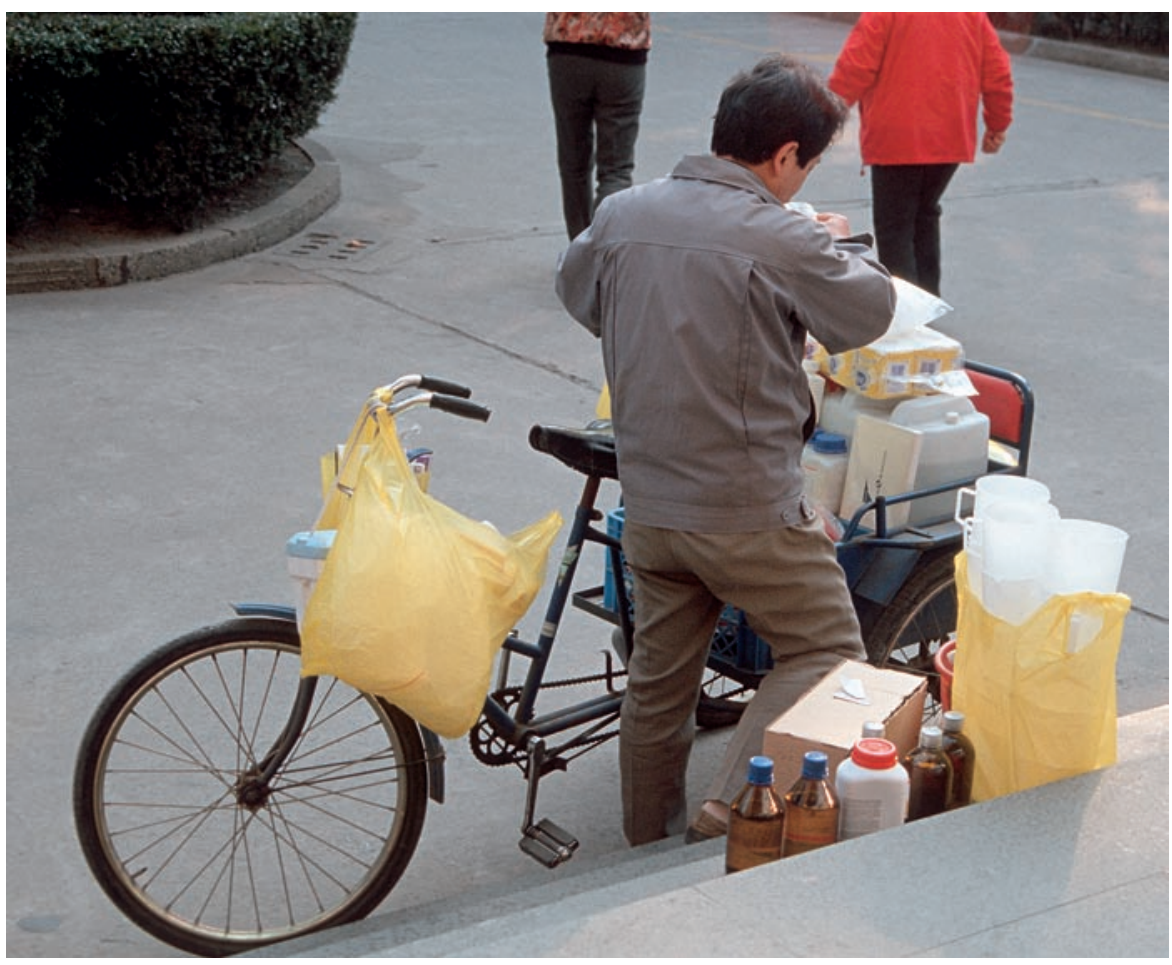

Fig 1 | Delivery service for laboratory consumables in Shanghai.

most major laboratories are reasonably or even well equipped, although the lower-level universities still have trouble obtaining the equipment and consumables that they need, not to mention the often poor laboratory conditions (Fig 2).

$\mathrm{F}$ or its part, the Chinese government has been considerably increasing its investment in scientific research. The 863 and 985 programmes of the Chinese Ministry of Science and Technology have provided substantial amounts of support for science-100 billion Renminbi (CNY; $€ 10$ billion) and 33 billion CNY (€3.3 billion), respectively, per year-although they must also provide funding for space activities and military research. However, the research grants available to support individual projects are far from adequate, especially when compared with European and US funding: 150,000 CNY, about $€ 15,000$, over $3-5$ years cannot cover the expenses of a research group, in particular as prices for equipment and consumables are still higher in China than in the EU or the USA (Wu, 2004). Moreover, as Chinese colleagues returning from Europe or the USA have told me, it remains difficult for them to obtain financial support if they are not well established within the Chinese scientific community.

Progress away from a culture in which political influence affected research towards a system driven more by quality has also taken place. As mentioned earlier, I joined many joint Chinese-European fellowship selection committees, which are usually composed of equal numbers of European and Chinese colleagues. Just six years ago, the Chinese members were still making obviously political decisions to promote certain candidates whose qualifications were questionable or clearly inadequate; today, their decisions are based much more evenly on qualitative considerations. In fact, I have enjoyed the informal and friendly environment present in such committees, which always seek consent between the members-quite a contrast to some stodgy European institutions.

T his positive experience does not, however, hold true for all cooperative activities between European and Chinese scientists. A mix of nationalist attitudes, administrative red tape, a lack of understanding of the support and the intentions of foreign partners, and poorly qualified Chinese scientists can have a severe impact on cooperative projects, depending on the partners involved. Nationalist attitudes are often encouraged by official Chinese policies, and there is a general wariness of foreign influence that is rooted at least as far back as the Opium Wars with the British (1839-1842). Even the youngest children are subject to ideological indoctrination about national pride and China's past suffering at the hands of foreign powers (Anon, 2008). This is in contrast to the attitude of, for example, the Vietnamese, who generally want to put the past in its place and to develop positive relationships with their former enemies.

A serious problem is that politics and political manoeuvring still have a large impact on matters that should be purely scientific. For example, the particular secretary of the Communist Party of China designated to any institution-be it a university, research institute or hospital-must ultimately approve all administrative decisions. In fact, the influence and involvement of such Party secretaries has been increasing again during the past years, since Jiang Zemin's term of office ended in 2003. This does not imply that the decisions made by Party secretaries are necessarily wrong or damaging; nevertheless, political cadres ought not to make decisions about scientific matters that they are not qualified to judge.

An example of this Party influence was the reversal-particularly just before the 2008 Olympic Games_of what had been increasingly open attitudes and promises towards international communication and collaboration; much the same happened during the Sichuan Earthquake in May 2008, when the flow of national and international information was eventually blocked after an initial period of openness.

The fundamental problem of the current Chinese approach to administration has already been described by my colleague, Thomas Zimmer, in a lecture he gave at the Chinese-German High School College at Tongji University in Shanghai (Zimmer, 2007): namely, the absence of transparency prevents rational decision-making and paves the way for corruption and irrational measures. The Chinese government is aware of the problem and has initiated formal processes to clarify individual responsibilities and to prevent illegal activities and corruption in selected regions of China, using these as a model. The success of these measures will, however, depend on how efficiently these policies are introduced and enforced; 
there is strong resistance to accepting personal responsibility at all administrative levels in China-a situation that is not surprising considering China's turbulent history and Confucian tradition.

I have come to the conclusion that much of this resistance is still shaped by the disastrous individual experiences since Mao Zedong's (1893-1976) rise to power and, in particular, of the Cultural Revolution in the 1960s and 1970s: people are still afraid to accept personal responsibility (Min, 1993, 1995). The absence of a truly independent judicial system also contributes to this situation and this will not change in the near future, as former Communist Party Politburo Standing Committee member, Luo Gan, has made clear: any reform of the judicature has to support the leading role of the Communist Party (Zimmer, 2007).

A major challenge for the Chinese educational system is to increase the general qualifications of its students if the country is to become internationally competitive in science. Generally, a Chinese biologist or biochemist at the postdoctoral level has had an education that is only equivalent to, or even below, that of an average Diploma degree student-roughly the equivalent of an MSc-in Germany. As a consequence, Chinese postdocs have a limited ability to work independently and demonstrate little originality in their selection of and approach to research subjects, or in the design of appropriate experiments. This is even worse for Bachelor and Master degree students, who often suffer from inadequate supervision.

The substantial pressure to deliver data and publications contributes to general deficiencies in scientific education and encourages the production of fabricated data- $\mathrm{a}$ situation not unique to China, but certainly present there in extremis. Anecdotally, I recently discovered that a $\mathrm{PhD}$ project submitted by an applicant for a fellowship was actually copied from a paper that had been published two years earlier in an international journal-entire sections were simply copied and pasted. Further investigation revealed that both letters of reference submitted - one of which was supposed to be from the intended Chinese supervisor-were also faked. Often, such behaviour is driven by a desire to survive despite miserable prospects for the future. Our Chinese colleagues and the government are well aware of these

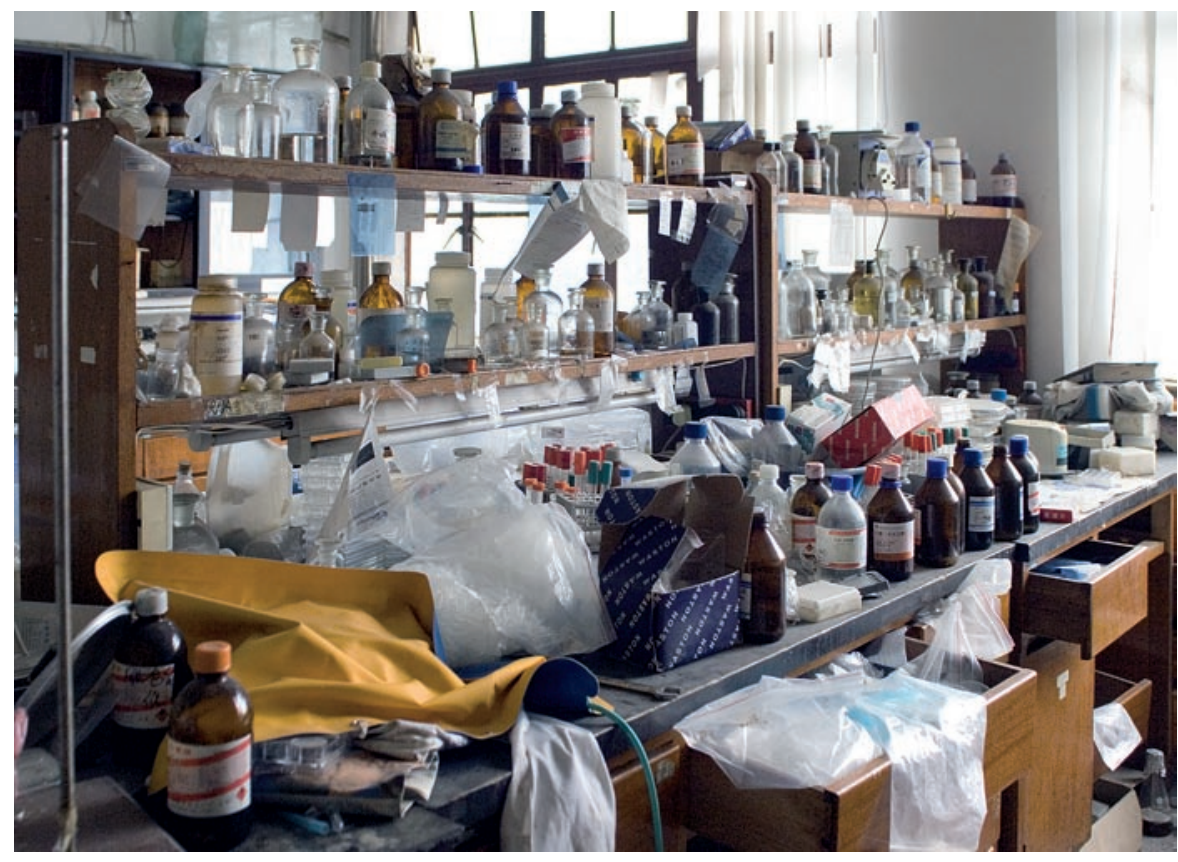

Fig 2 | Laboratory conditions are often not suitable to encourage professional laboratory work.

problems, and have begun to implement possible countermeasures (Jia, 2006; Yu, 2006; Anon, 2006).

Mastering English, the lingua franca of the scientific community, still poses a considerable problem for most Chinese students. Although most are able to read English, oral communication is still difficult for many students, especially for those who come from remote provinces. A related problem is that students are generally reluctant to admit that they do not understand precisely what has been discussed. I have therefore found it essential to ask most Chinese students to repeat the important points of a discussion to make sure that they have understood correctly.

I and other colleagues have also found-in the context of fellowships provided by DAAD - that Chinese students and postdocs who work abroad often do not understand or even accept the regulations about animal protection, waste disposal and laboratory safety, for example. This is not surprising, as such regulations are few and far between, and those that are in place are usually ignored or are not monitored (Hennig, 2006), even with regard to working with radioactive substances. I have found that some students do not even see a need to learn about basic safety procedures. This situation is a major difficulty in educating European or other foreign students in Chinese laboratories, as they become exposed to careless practices. The negligent behaviour of Chinese students has already led to unfortunate consequences in laboratories in Europe and the USA.

The situation of female scientists in China also deserves attention. According to the constitution of the Peoples Republic of China, both genders should have equal rights. However, the reality - as in many other and in particular Asian countries-is different to the stated policy: the number of female scientists in leading positions is extremely low $(\mathrm{Wu}, 2008)$, even though the number of female students is approximately equal to that of male students. I generally found female students to be more motivated and often better qualified than male students who, nevertheless, remain convinced of their superiority.

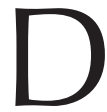
espite the significant economic progress made by China during the past years, the general economic situation of students has not fundamentally changed. High tuition fees and high living costs in the large cities create a considerable financial burden for families who want to give their children a good education. Families from rural China find it 
especially hard to finance their children's academic education. Although fellowships are available to cover tuition fees and provide basic support for living expenses for some students, the living conditions are still unsatisfactory-for example, there is usually no air conditioning or heating to mitigate temperatures that fluctuate between $0{ }^{\circ} \mathrm{C}$ and $40^{\circ} \mathrm{C}$ in Shanghai, students often live in shared rooms with 4-6 beds, and their lodgings suffer from poor hygiene and other sub-standard facilities-a situation that few if any European or American students can imagine.

\section{Most students have a strong preference for business schools and management courses, whereas the interest in basic research has been declining...}

A serious problem for Chinese higher education-and for the future development of research in China-is the prevailing interests of the students who enter the universities. Most students have a strong preference for business schools and management courses, whereas the interest in basic research has been declining; the capitalistic mantra of 'making money' is now the Chinese dream, although the country considers itself to be a communist society implementing Chinese socialism. This is a matter of concern in a country that has still to re-establish a cultural identity after almost 150 years of imperialism, civil war, international war and communist rule, and that has, to a large extent, erased much of its cultural tradition. In fact, notwithstanding all of the positive developments that have taken place in China during the past two decades, my experience is that the desire of the Chinese to go abroad to find better education and living conditions is even more prevalent today than it was in the 1980s and 1990s. In recent years I had great difficulty keeping Chinese students in my research group, and most of them left after a few months, sometimes ignoring all contractual obligations. In essence, some students were really looking for a position in the USA or Europe and only joined my laboratory to gain a reference for their applications to foreign universities.

Another educational deficit is the lack of practical education at Chinese universities and other educational institutions: Chinese students tend only to have to memorize theoretical knowledge. Moreover, individual initiative, questions and critical discussions are not welcome, nor is the development of creative ideas. This might, in part, be due to a lack of trained teachers and lecturers, especially at the middle levels of the university system, as well as a lack of training in teaching practical skills. However, it also seems that it is convenient for the Chinese educational authorities to maintain the traditional educational system, which minimizes the effort required from a teacher and supports the political system.

In my experience, this attitude demotivates students - a problem that is compounded further by the difficulties of finding a research or teaching position after graduation. Many students eventually realize that only one or two of every 1,000 biology graduates might find appropriate positions-and that these will be the two students with the best connections, not with the best qualifications. Indeed, scientific qualifications are usually not the most important criteria for securing a position, and even if they were, the lack of available positions would still prevent most well-qualified students from finding a research post.

M y professorship at the Johannes Gutenberg University in Mainz, Germany, has meant that I have trained some 40 German students at various educational levels for periods between 3 and 12 months - sometimes even longerin my Shanghai laboratory. I have also guided them through their respective examinations in Germany. For the most part, the German students greatly enjoyed the opportunity to work abroad, although living and working in China certainly created all types of practical problems, particularly as working conditions were not comparable with the standard of a German laboratory. Still, for many of the Bachelor or Master students it was the experience of a lifetime to spend some time exploring China and working in a Chinese laboratory.

Yet, these students still had to meet the requirements for passing a thesis examination at a German university, and this difficult task could only be achieved by subdividing their work into separate projects, each of which could be continued independently of the others depending on when the required materials became available. German students in other (Chinese) groups needed a 'home base' in Germany with complementing facilities to support them with their PhD theses. Nevertheless, most of the students considered their stay in China to be a good education in solving unexpected problems. The only experience that they strangely missed was the weekly political education that is still mandatory for Chinese students and staff. However, the level of political indoctrination is generally decreasing and, compared with the situation just one decade ago, private conversations are reasonably free and can be very critical of the government; a sure sign that times are changing and that the Party is no longer able to keep criticism suppressed.

A s I mentioned earlier, many of the difficulties faced by researchers in China are caused by the long delivery times required for laboratory materials, which is not made easier by administrative red tape. During the 1980s and early 1990s, it was easy to obtain missing material by simply asking colleagues in Germany to send it by airmail; I usually managed to obtain enzymes and other consumables within 2-3 days of calling my colleagues in Tübingen. We could pick up the mail from the Chinese customs office at Shanghai Airport immediately on arrival and take care of the paperwork later. As the rules and regulations controlling the ordering of research material have increased, and as customs procedures have tightened, this is no longer possible. It took me three months to obtain the parts needed for micromanipulation and I was not able to import a micro forge at all, even though it was my personal property. The customs office charges a fee for storing any material; thus, rather cynically, increasing the time required to clear paperwork is just a good way to make money. Some materials are even impossible to obtain: Drosophila strains, for example, do not pass customs. A discussion within SIBS ended with the statement that it might take another 20 years to solve such problems. Generally, there is only one Chinese company in the whole country that is certified to import animals, and it still takes months.

Another administrative problem is that only $20 \%$ of a research budget can be spent on employing research staff, whereas the remaining budget is assigned to consumables without consideration of the particular tasks of the laboratory. Obviously, an institute dedicated to computational biology does not spend $80 \%$ of its money on computers and printer paper; it clearly has a larger 
need for manpower, and so this arbitrary division makes little sense. Furthermore, participation at meetings abroad has been considerably restricted, even for foreigners, and comes with an excessive volume of administrative requirements. Absurdly, the same money can be used to invite guests to dinners or on sightseeing tours in China; although Western visitors generally enjoy this hospitality, it remains a valid question whether a country that still needs to improve its research base can afford such generosity. I always felt uneasy about accepting such invitations as I knew that I was experiencing benefits that are not available to most Chinese. Another peculiar feature is that the directors of research institutes can freely decide how to spend $10 \%$ of their institute's budget, which, altogether, is a considerable amount of public money that is being spent without appropriate controls.

W orking as a foreigner in the Chinese research system is a rewarding experience because it provides the opportunity of intense interactions with Chinese students and the experience of a different culture; however, it still poses major challenges. One problem is that contracts are generally not considered to be binding. Moreover, what Western scientists understand as 'freedom of research' is not a well-accepted concept in the Chinese academic environment. One major project set up by the German director of our institute was to establish a microscopy facility, called the Toponome Center, in 2006 (Schubert, 2006). The German partner guaranteed the financial support, but, to this day, the Chinese side has blocked the installation of the necessary equipment without ever revealing the actual reasons. Similar problems have emerged at Tongji University in Shanghai: a European colleague had originally planned to purchase scientific instruments from a European company, but was instead forced to use Chinese products, which are not adequate for the intended tasks.

Foreign scientists and students can also experience various serious visa problems that are unpredictable and change continuously. One of our students has been threatened with prison if he does not extend his visa after three months in Germany. Residence permits are difficult to obtain, even for employees of academies and universities. This is often a problem of local politics and obviously depends on individual decisions rather than official rules, which again is the result of an absence of clear administrative regulations.

A Ithough it might seem that my comments in this Viewpoint are quite critical of Chinese research and universities on the whole, I rather regard my role to be one of pointing out problems, which, in my view, are hindering the future development of research in China and especially its interactions with Western countries. These concerns are not only my own, but are shared by other foreign and even Chinese scientists. In addition, by giving a realistic description and a personal experience of the conditions that European scientists have to face in China, I hope to make it clear that moving to work in China is a decision that requires serious contemplation, as it can have a potentially negative impact on a career in science. A second base in a European country or in the USA is essential for any successful work. At present, it is mostly retired scientists, such as myself, who can afford to live and perform laboratory research in China, simply because we no longer depend on publications and short-term research performance, and rather see our main task to be educating students. This might be less critical in purely theoretical work.

China has made enormous progress in the biological sciences, and has created and supported a considerable research base. This is even more impressive in light of the fact that Chinese scientists started from almost nothing - a situation that was not only caused by the Lysenkoism inherited from the Soviet Union, but that was also a consequence of the political turbulence of the past 150 years. China's success is also reflected in the increasing number of Chinese publications in moderately ranked international journals, although publications in higher-ranking journals are still mostly in cooperation with collaborators in the West. Chinese publications in plant molecular biology in Science Citation Index publications have increased from less than $2 \%$ in 1994 to about $10 \%$ in 2008. The average citation impact performance of publications has increased from less than 0.5 to 1.0 from 1996 to 2003 . Some $30 \%$ of the publications are from international cooperations (Jonkers \& Thijssen, 2008).

This development will continue, but China's future success depends greatly on other changes that need to be made in the country. First, the education system needs fundamental revision to generate students who are able to compete internationally. This will require that more qualified Chinese scientists return from abroad both to improve university teaching and to raise the general standard of research. However, Chinese scientists who have returned have told me that they found it hard to reintegrate into the Chinese research community, perhaps because the traditional attitude of many Chinese scientists is to keep their laboratories carefully isolated from each other, rather than seeking interactions and cooperation. Stimulating interactions between groups and institutions, improving working conditions and encouraging international research interactions are crucial to the advance of Chinese research. China will also have to improve the job prospects - that is, the number of appropriate research positions available - for its graduates, otherwise the brain-drain of Chinese scientists to North America, Australia and Europe will continue, and the most successful researchers will stay abroad.

\section{China has made enormous progress in the biological sciences, and has created and supported a considerable research base}

Interestingly, many of the efforts of foreign scientists and teachers to improve the academic environment are accepted only hesitantly in China or are even considered to be undesirable, as they cause friction against traditional Chinese teaching habits and social relationships. Over the years, others and I have experienced the sentiment that China does not want foreigners to impose a new form of educational or research 'colonialism', which probably reflects unofficial Party thinking about foreign values and interaction. Perhaps understandably, this perception is likely to be based on China's history with Western and other Eastern powers; historical events still affect decision-making in China today and tend to encourage emotional or even aggressive nationalist views. However, I am convinced that if China were to better integrate and support foreigners working in China-in particular, in the Chinese education and research systems - it would greatly help to promote successful practices in academic research and teaching, ultimately allowing Chinese research to be competitive in the international scientific arena. 
REFERENCES

Anon (2006) Finding fraud in China. Nature 441: 549-550

Anon (2008) Die chinesische Seele. Die Zeit,

July 17

Hennig W (2000) Molecular biology, China and the West. 15 years of teaching at the Max Planck Guest Laboratory in Shanghai. EMBO Rep 1: 457-459

Hennig W (2006) Bioethics in China: although national guidelines are in place, their implementation remains difficult. EMBO Rep 7: 850-854

Jia H (2006) Fighting against fabrications in China's academia. China Daily, April 29

Jonkers K, Thijssen R (2008) Chinese researchers returning home: impacts of international mobility on research collaboration and scientific productivity. Scientometrics 77: 309-333

Min A (1993) Red Azalea. London, UK: Victor

$$
\text { Gollancz }
$$

Min A (1995) Katherine. New York, NY, USA: Berkley Books

Schubert W et al (2006) Analyzing proteome topology and function by automated

multidimensional fluorescence microscopy. Nat Biotechnol 24: 1270-1278

Wu L-A (2008) Fix the gender ratios. Nature 454: 399

Wu R (2004) Making an impact. Nature 428: 206-207

Yu Z (2006) Code set to safeguard academic ethics. China Daily, May 24

Zimmer T (2007) China aktuell. China Report 46: $1-11$

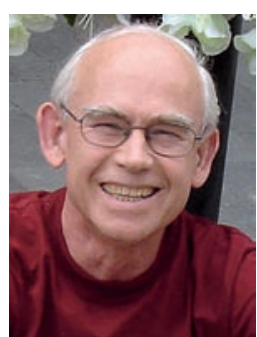

Wolfgang Hennig is at the Institute of Genetics, Johannes Gutenberg University, Mainz, Germany. E-mail:whennig@gmx.de

doi:10.1038/embor.2009.114 